\title{
Investigación, evidencia
}

e interpretación en el documental

Los rollos perdidos, de Gibrán Bazán

INVESTIGATION, EVIDENCE AND INTERPRETATION IN THE DOCUMENTARY LOS ROLLOS PERDIDOS, BY GIBRÁN BAZÁN

Héctor Fernando-Vizcarra*

* Universidad Nacional Autónoma de México, México

Correo-e: hf.vizcarra@gmail.com

Recibido: 7 de diciembre de 2020

Aprobado: 29 de junio de 2021

Resumen: Se analizan las estrategias que el documental mexicano Los rollos perdidos (Gibrán Bazán (dir.), 2012) emplea para persuadir al espectador de la importancia de recuperar la memoria de dos sucesos de la historia reciente: la matanza del 2 de octubre de 1968 en Tlatelolco y el incendio de la Cineteca Nacional en 1982, así como la conexión sugerida entre ambos eventos a partir de las filmaciones del cineasta Servando González en la Plaza de las Tres Culturas, llevadas a cabo bajo el auspicio del gobierno. Para ello, nos basamos en las nociones de 'experiencia', 'exposición de evidencia' e 'interpretación persuasiva' que Bill Nichols desarrolla en su libro Introducción al documental (2013).

Palabras clave: archivos cinematográficos; director de cine; filmoteca; película; documental; película histórica; movimiento político; represión

Abstract: The strategies that the Mexican documentary Los rollos perdidos (Gibrán Bazán (dir.), 2012) employs to persuade the viewer of the importance of recovering the memory of two events in recent history: the massacre of October 2, 1968 in Tlatelolco and the 1982 National Cinematheque fire, as well as the suggested connection between the two events based on the filming of the filmmaker Servando González in the Plaza de las Tres Culturas, carried out under the auspices of the government. To do this, we rely on the notions of 'experience', 'evidence exposition' and 'persuasive interpretation' that Bill Nichols develops in his book Introduction to documentary (2013).

Keywords: film archives; film maker; film libraries; film; documentary film; historical film; political movements; oppression 
$\mathrm{E}$ 1 largometraje Los rollos perdidos (Bazán (dir.), 2012) documenta un par de investigaciones relacionadas con material fílmico esencial para comprender el movimiento estudiantil mexicano de 1968, sin duda, uno de los sucesos de mayor repercusión en la historia nacional contemporánea. En dicha época, las filmaciones y grabaciones audiovisuales, sin llegar a la presencia abrumadora que tienen en la cotidianidad actual, estaban ya normalizadas como parte imprescindible del trabajo periodístico y de la documentación testimonial.

La pérdida, destrucción o desaparición de varios rollos de película filmados durante la matanza del 2 de octubre en Tlatelolco, realizados presuntamente por el director de cine Servando González desde puntos estratégicos en los alrededores de la Plaza de las Tres Culturas, nos permitirá reflexionar en las páginas siguientes sobre el posicionamiento ético de los dos cineastas (Gibrán Bazán en su película, a manera de metacomentario, y Servando González en sus rollos testimoniales, como probable cómplice del régimen que le encargó la filmación), posturas antagónicas que, de acuerdo con las teorizaciones sobre el cine documental, son inherentes a dicho formato de discurso audiovisual (sin que esto implique, forzosamente, una valoración positiva o negativa de ambos casos en el presente trabajo).

Mediante las nociones de 'experiencia específica y general', 'exposición de evidencia' e 'interpretación persuasiva' descritas por Bill Nichols en su libro Introducción al documental (2013), me interesa explorar las estrategias documentales y los posicionamientos de ambos directores frente a la memoria histórica del siglo XX mexicano, en específico, la represión del 2 de octubre de 1968 y el incendio de la antigua Cineteca Nacional ${ }^{1}$ ocurrido el 24 de marzo de 1982. Este

1 "La Cineteca Nacional abrió sus puertas el 17 de enero de 1974 en la esquina de Avenida Río Churubusco y Calzada de Tlalpan al sur de la Ciudad de México [...]. Se construyó en uno de los Foros de los Estudios Churubusco (ECHASA), y último siniestro dejó varias personas muertas y material quemado e inservible que, según el documental analizado, hizo acreedor a México del récord Guinness de mayor cantidad de películas perdidas en un solo día (2012). ${ }^{2}$

Las líneas argumentales y de investigación de Los rollos perdidos segmentan en dos mitades (casi de la misma extensión) los 94 minutos de duración total del filme. La primera trama abarca la presunta filmación de la masacre de Tlatelolco desde el edificio de la Secretaría de Relaciones Exteriores, tarea encomendada al cineasta mexicano Servando González ${ }^{3}$ por el secretario de Gobernación Luis Echeverría. La segunda trama, que inicia aproximadamente en el minuto 37 del documental, aborda el incendio de la antigua Cineteca Nacional, basándose en testimonios directos, grabaciones de noticieros de la época (en particular el de ese día, 24 de marzo, transmitido por Televisa y conducido por Jacobo Zabludovsky) y especulaciones sobre el origen y trasfondo del accidente.

Las estrategias discursivas del género documental utilizadas por Gibrán Bazán sugieren, insistentemente, una confluencia de estas dos tramas que genera, a su vez, una tercera implícita, según la cual el metraje sobrante de la filmación hecha en 1968 podría haber estado escondido, olvidado o simplemente confundido entre muchos otros rollos enlatados en la cineteca que

en ese entonces estaba adscrita a la Dirección de Cinematografía de la Secretaría de Gobernación del Ejecutivo Federal. La conformaban dos salas de proyección abiertas al público (Salón Rojo y Sala Fernando de Fuentes), y tenía además un área de exposiciones periódicas; una hemeroteca-biblioteca especializada; una librería; un restaurante; cuatro bóvedas de seguridad para el almacenamiento de filmes con temperatura y humedad controladas; y un taller de mantenimiento y reparación de películas" (CONACULTA, 2012: 8).

2 Todas las citas pertenecientes a Los rollos perdidos corresponden a Bazán (dir.) (2012), por lo cual sólo se anota el año de producción.

3 Ciudad de México, 1924-2008. Entre sus principales películas están Yanco (1960), Viento negro (1964), El escapulario (1966) y Los de abajo (1976), según la videoentrevista Servando González de la serie Memoria del cine mexicano (Pelayo Rangel, 1993), cuyos fragmentos son recuperados e insertos en el documental Los rollos perdidos. 
se incendió catorce años después de la masacre. Si el documental que nos atañe está segmentado en dos partes equivalentes, con dos premisas de investigación en primera instancia alejadas, la que podemos llamar 'tercera trama' subyace en el transcurso de todo el filme para, hacia los últimos quince minutos, incrementar las sospechas del espectador, a quien se le ha estimulado con noticias y testimonios que, se espera, lo vinculen emocionalmente con el punto de vista de la obra audiovisual (es decir, la perspectiva del equipo de producción de Los rollos perdidos).

La nota textual que inicia la película de Bazán asegura que, de entre las personas invitadas a conversar sobre los temas, más de cincuenta "se negaron a conceder entrevistas a los realizadores" (2012). La voz en off del actor mexicano Daniel Giménez Cacho introduce la primera trama, asegurando que Servando González "fue contratado por la suma de 20000 pesos por el gobierno mexicano para filmar con ocho cámaras de $35 \mathrm{~mm}$ una manifestación que tendría lugar el 2 de octubre, la cual sería dispersada con mano dura por parte del ejército" (2012). Antes de los testimonios recopilados sobre la presunta filmación, aparecen a cuadro las pocas imágenes conocidas que fueron grabadas en Tlatelolco el 2 de octubre, mismas que desde entonces han aparecido en múltiples documentales y programas de televisión alternadas con las palabras del presidente Gustavo Díaz Ordaz frente al congreso durante su cuarto informe de gobierno (1 de septiembre de 1968). En dicho discurso, también muchas veces reproducido, el mandatario habla sobre la paz nacional puesta en riesgo, la relevancia de los Juegos Olímpicos (inaugurados el 12 de octubre del mismo año) y los límites de la paciencia del Estado frente a las desproporciones del movimiento estudiantil. De esta manera, la combinación contrastante de las imágenes de la represión y la arenga patentemente amenazadora sirve de preámbulo, de preparación al espectador, para esa primera mitad de LoS rollos perdidos. Es decir, mediante una edición alternada a manera de secuencias paralelas, en esos primeros minutos se deja en claro el efecto de confrontación e incompatibilidad de ambos discursos, entre los cuales el espectador, idealmente, debe tomar partido.

Esta suerte de apertura o íncipit del documental de Bazán, que antecede a la aparición de los créditos iniciales, apela a nuestro conocimiento previo del hecho histórico (incluidos los juicios colectivos y personales), es decir, a nuestra experiencia formada con antelación. Es difícil pensar que, al menos entre el público mexicano urbano y con nivel escolarizado medio o alto (al que principalmente se dirige el documental), existan quienes desconozcan totalmente los sucesos del 2 de octubre, pero aun si fuera el caso (pensemos en una proyección de Los rollos perdidos en el extranjero), las imágenes iniciales funcionan como vehículo para contextualizar la matanza, los responsables de llevarla a cabo y las víctimas, al tiempo que invita a solidarizarse con éstas últimas y, con ello, hacer conciencia de una circunstancia histórica concreta, pero que sin duda puede ser ligada a cualquier otra represión, estudiantil o no, en otro tiempo y lugar. De acuerdo con Bill Nichols,

\footnotetext{
[1]os documentales usualmente contienen una tensión entre lo específico y lo general, entre momentos históricamente únicos y generalizaciones [...]. La mayoría de los tópicos que identificamos como lugares comunes del cine documental (la guerra, la violencia, la biografía, la sexualidad [...]) son abstracciones derivadas de experiencias específicas. Son modos de empaquetar la experiencia y convertirla en categorías, marcos o estructuras gestálticas (2013: 124).
}

En ese sentido, al visualizar Los rollos perdidos, la denominada 'experiencia general' está conformada por el grado de información que el público posee sobre la violencia vertical y la impunidad del Estado mexicano (mismas que se extienden 
claramente hasta nuestros días, incluyendo la criminalización de las manifestaciones, en particular las hechas por jóvenes y estudiantes). Por otro lado, la 'experiencia específica', el momento "históricamente único" al que alude Nichols, es lo sucedido en Tlatelolco, como si se hubiera tratado de un incidente aislado cuya sola fecha remite al acto de represión más conocido del México contemporáneo. Ambas experiencias son agrupadas para crear, desde los primeros minutos del largometraje, empatía con la evaluación ética negativa que apunta hacia la figura de Servando González en tanto cineasta, luego de tener la certeza de que dichos rollos, filmados por encargo gubernamental, existen o existieron.

Si bien la mayor parte de las producciones documentales o de ficción (ya sea literarias, plásticas o audiovisuales) sobre el movimiento estudiantil de 1968 someten a juicio a los responsables y ejecutores de la masacre (de Echeverría al cuerpo de granaderos, del coordinador de la policía del entonces Distrito Federal, Luis Cueto Ramírez, al Batallón Olimpia), Gibrán Bazán apuesta por un proceso de revisión del papel de Servando González en su posición de creador artístico ligado al régimen (una suerte de intelectual orgánico) $\mathrm{y}$, en consecuencia, de su ética como cineasta. Esa acusación se sostiene en la premisa del creador como agente colaborador y al servicio del poder, quien, a diferencia del 'artista comprometido', utiliza sus bagajes intelectuales y técnicos para refrendar, justificar, elogiar y conservar el statu quo. Las palabras de Servando González, incluidas en la entrevista inserta en el largometraje de Bazán, lo confirman: "Yo tuve ocho cámaras presenciando los problemas de Tlatelolco. Desde muy temprana hora, desde las tres de la tarde, emplacé cámaras por todos lados. Yo vi el paracaídas, yo vi todos los muertos. En cine está todo eso" (2012). A su vez, las opiniones sobre González y su actuación durante el desarrollo del movimiento estudiantil ofrecen, mediante el contraste de una edición que se asume como diálogo, una perspectiva completamente opuesta. Por ejemplo, dice el cineasta Óscar Menéndez, uno de los entrevistados más recurrentes del documental: "Estas filmaciones a cargo de Servando González, que manejaba a este equipo de criminales que se dedicaban al cine también [...], ellos tenían absolutamente todo el registro, lo tienen ellos, desde el 26 de julio hasta el 2 de octubre" (2012'). Ambas declaraciones alternadas enuncian los datos duros a partir de los cuales se configura la perspectiva del documental, pues incluyen, desde esos primeros minutos del largometraje, la evidencia testimonial, la experiencia (general y específica) y, como resultado, la interpretación definida, tanto de Servando González como de una sección del gremio de cineastas afín al movimiento. Para Bill Nichols,

[u]n documental es más que evidencia: es también una manera particular de ver el mundo, haciendo propuestas acerca de él $u$ ofreciendo perspectivas acerca de él. Es, en ese sentido, un modo de interpretar al mundo. Para hacerlo, utilizará evidencia (2013: 56).

De tal forma, las pruebas expuestas en Los rollos perdidos son de carácter testimonial, pues se apoyan en declaraciones directas de trabajadores de la industria fílmica mexicana en las que participan investigadores y críticos, como Juan Jiménez Patiño y Jorge Ayala Blanco, además de los cineastas Nicolás Echevarría, el ya citado Óscar Menéndez, Alfredo Gurrola e incluso el propio Servando González en la entrevista referida arriba. La visión del mundo a la que se refiere Nichols está presidida, en el documental que nos ocupa, por dichas intervenciones, de entre las cuales sobresalen comentarios que, literalmente, acusan al director de cooperar tangencialmente con la represión. Frases como "una canallada cinematográfica”, "comportamiento servil y asesino", "un artista que puede prestarse a esas bajezas" expresan, por decir lo menos, el descontento, la contrariedad y la decepción ante las acciones de Servando González, pero aún más en 
concreto, emiten un posicionamiento definido en contra del creador y de prácticas de esa índole, (“mercenarias, despreciables, sin vergüenza”, a decir de uno de los intervinientes), un posicionamiento ético y político no sólo de quienes conceden las entrevistas, sino, por extensión, también de Gibrán Bazán, la voz que proporciona una identidad propia al documental.

Efectivamente, entendiendo por 'voz' el enfoque propuesto por el film, la primera trama de Los rollos perdidos juzga el proceder de Servando González y, para darle sustento, apela a gente que conoció a dicho cineasta y opina sobre él. Alfredo Gurrola, director de la película de culto Llámenme Mike (1979), afirma: "Él [Servando González] siempre mantuvo una secrecía de todo lo que pasó. [...] Porque el haber filmado para gobernación, para Luis Echeverría en este caso, directamente, manifestaba una cierta posición, o lo etiquetaba dentro de una posición política" (2012). Humberto Campos, miembro del Comité 68 , asegura que el cineasta "siempre se manejó como lo que era: el hombre de confianza de la presidencia. Él tuvo muchos privilegios por esa situación, tan servil y tan asesina" (2012), aseveraciones que forjan un juicio extremadamente severo sobre la relación entre González y el poder. Sobre todo, se apela a que el artista aprovechó su condición de creador con una carrera consolidada, por lo cual se hace énfasis en su oportunismo, tanto político como económico, al sacar partido de un posicionamiento conveniente, alineado, durante una etapa coyuntural del México moderno en la que, además, la mayoría de los partícipes del campo cultural simpatizaba con las demandas de los estudiantes.

$\mathrm{Si}$, como las voces del documental nos comunican, Servando González decidió plegarse a la voluntad del poder político, existen razones viables para suponer que accedió a grabar en Tlatelolco y, después, entregar el material a quien le hizo dicha encomienda. Según las opiniones recabadas, González fue un 'vendido' a las altas esferas del poder político, que lo recompensaron con viajes, recursos y preferencias en el acceso a financiamientos para realizar sus películas, algo que, en palabras de este controvertido cineasta, se definiría como lealtad:

Porque si algo tengo, es ser grato [dice Servando en la entrevista ya mencionada], y la gratitud [...] es uno de los valores más grandes del hombre. Y fui grato con el señor presidente López Mateos hasta su muerte, lo llevé al cementerio, y también a la señora López Mateos, [pues] estuve pendiente de su enfermedad hasta que murió (2012).

El montaje alternado de las entrevistas ratifica, por un lado, el compromiso de los intelectuales y artistas con los ideales representados por el movimiento estudiantil, y, por otro, la gratitud de algunos hacia los gobernantes. En ambos casos, persiste la idea particular de dos éticas antagonistas. Una declaración contundente de Óscar Menéndez sintetiza la visión más radical y arriesgada del largometraje:

¿Qué cineasta puede decirse que tiene honor o tiene ética cuando hace un trabajo para los criminales que planearon la matanza del 68? [...] Son unos seres despreciables estas gentes que hicieron esta filmación [...] y todavía se sienten orgullosos (2012).

De ida y vuelta, en ese entramado de voces, el espectador asimila las experiencias personales y grupales de quienes, desde flancos distintos, fueron partícipes de un acontecimiento que, paradójicamente, no es el mismo, dado que ha sido atravesado por filtros de nociones éticas contrapuestas: una que se consagra al silencio, a la complicidad, y otra que persevera en la denuncia y en el señalamiento de los culpables. Así, los testimonios nos parecen confiables porque, en primer lugar, reafirman el punto de vista de Los rollos perdidos, dado que, como argumenta Nichols, 
[el documental] habla acerca de situaciones y sucesos que involucran a gente real (actores sociales) que se presentan a sí mismos ante nosotros en historias que transmiten una propuesta plausible acerca de, o una perspectiva respecto a, las vidas, situaciones y sucesos retratados (2013: 35).

En segundo lugar, los testimonios transmiten la propia ética del documental que nos ocupa y de sus realizadores, pues, siguiendo con el razonamiento de Nichols, "[e]l punto de vista particular del cineasta moldea de tal manera la historia, que vemos de manera directa el mundo histórico, más que en una alegoría ficcional" (2013: 35. Las cursivas son mías). Subrayo el hecho de que, para el teórico estadounidense, el cineasta moldea (en otras palabras, manipula) la historia para dar continuidad a su argumento y cohesión a la ética que propugna, lo cual es mucho más relevante en el caso del cine documental que en el de ficción, dado que, como hemos dicho, se pone en juego la verosimilitud (como sucede en todo pacto discursivo), pero, más aún, la veracidad de lo que se proyecta al público.

En consecuencia, la recuperación de la experiencia y la memoria, seguida por el despliegue de evidencias de testigos, articula el discurso crítico de Los rollos perdidos. En este punto, el espectador muy probablemente compartirá la perspectiva de Gibrán Bazán y su equipo. La aparición a cuadro del grupo de investigación del documental, mientras visita el piso 17 del edificio de la Secretaría de Relaciones Exteriores y especula sobre la disposición de las cámaras prestadas a Servando González, confiere un tono de veracidad tanto a los testimonios como a la denuncia explícita de esta obra, con lo cual se construye, o se pretende construir, una nueva experiencia específica en el espectador: el hecho de que,

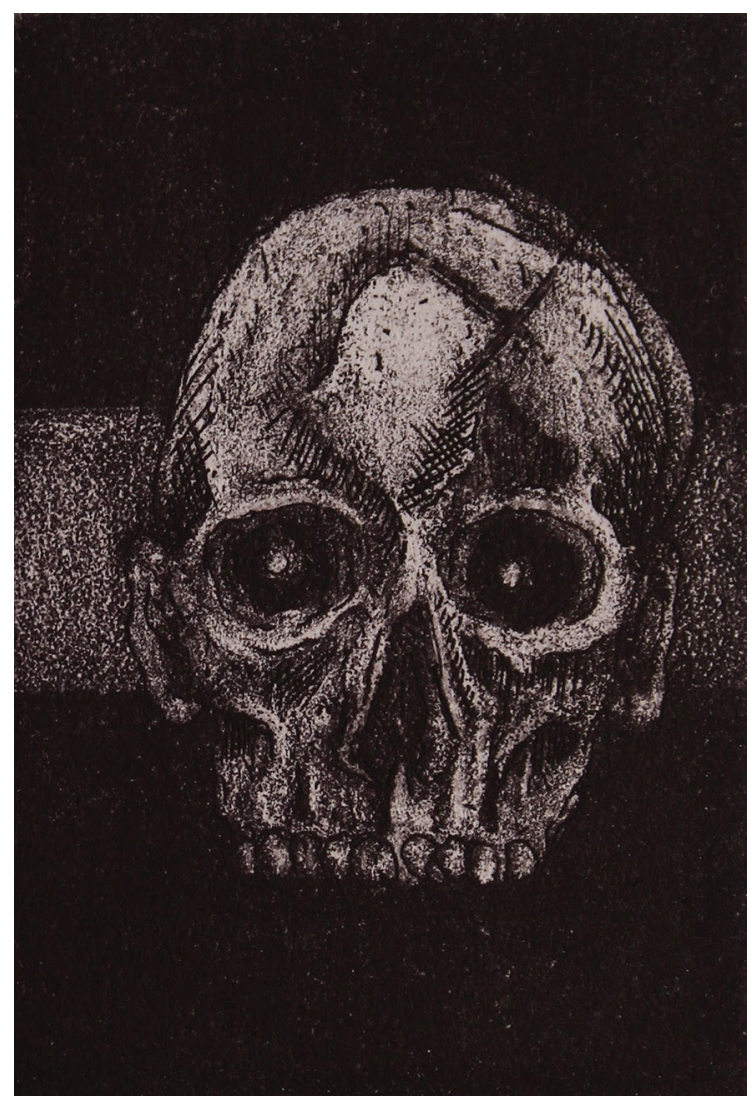

Delirios de una agonia prolongada (s/f ). Colografía: Juan Manuel Martínez Jaramillo. Prohibida su reproducción en obras derivadas. 
paralelamente a la represión, los sucesos del 2 de octubre fueron captados visualmente desde un punto estratégico, en catorce rollos equivalentes a más de ocho horas de filmación.

En este sentido, la experiencia, la exposición de evidencia y la interpretación persuasiva como estrategias de enunciación establecen un pacto de credibilidad entre Los rollos perdidos y el receptor, con lo cual se obtiene una estabilidad de esa visión del mundo, misma que es necesaria para acceder a lo que líneas atrás he denominado 'segunda trama': el incendio de la Cineteca Nacional en 1982.

Por su naturaleza investigativa, incluso desde el clásico de Robert J. Flaherty, Nanook of the North (1922), el documental posee analogías con las narraciones detectivescas. Esta correlación ha sido advertida por la crítica literaria dedicada al género policial, tras demostrar la semejanza estructural y temática entre el periodismo y la ficción de detectives, cuyo nacimiento se produce a mediados del siglo XIX, época en que también se consolida la masificación de los medios de comunicación impresos. Si bien la pregunta necesaria en un relato policial clásico suele ser iquién es el culpable?, lo que en realidad se narra (y engancha al lector) es el proceso de detección, esto es, la tarea de rastreo del detective y, conclusivamente, su interpretación y veredicto sobre el misterio. De este modo, con las pautas de dicho proceso de averiguación, Los rollos perdidos, en tanto documental que toma una posición reconocible, aporta pruebas casi irrefutables sobre la filmación gubernamental en la Plaza de las Tres Culturas. La segunda mitad del largometraje, de carácter fuertemente especulativo, tiende mucho más a la formulación de hipótesis, pues la única certeza de la que se parte es el incendio de la cineteca. Para Bill Nichols,

[e]l documentalista ve hacia el pasado y hace preguntas como ¿qué sucedió realmente? Son preguntas de hechos e interpretación, en donde está en juego la culpabilidad y la inocencia, en relación con la ley, y están en juego la verdad o la falsedad, en relación con la historia (2013: 130).

En efecto, la pregunta que conduce la segunda trama del documental no es, propiamente, ¿quién incendió la cineteca? (aunque es cierto que algunos de los entrevistados lanzan acusaciones frontales), sino las siguientes incógnitas: ¿se trató de un fuego provocado?, ¿qué había en la cineteca incendiada?, ieran ciertos los rumores de que los rollos filmados por Servando González estaban en algún lugar del recinto?

Sin duda, como si se tratara del entramado de una narración de detectives, la anterior serie de cuestionamientos exhorta al público espectador a creer que esos rollos se encontraban ahí e, incluso, que las llamas fueron provocadas intencionalmente para destruirlos. No hay, sin embargo, ninguna prueba de esto.

A la pregunta ¿qué sucedió realmente?, que de acuerdo con Bill Nichols es el detonador de cualquier proyecto de cine documental (2013: 130), se postulan diversas conjeturas: tres o siete explosiones detrás de la pantalla de la sala Fernando de Fuentes; una explosión en el restaurante contiguo; un atentado contra Margarita López Portillo, directora general de Radio, Televisión y Cinematografía (RTC), quien esa noche visitó la cineteca; un accidente ocasionado por el almacenamiento inadecuado de material inflamable, ubicado justo detrás de la pantalla; de tres a cinco muertos, y un número desconocido de personas desaparecidas, entre 4000 y 10000 rollos quemados, así como acervos fotográficos y guiones. Ninguna de estas cifras oscilantes es comprobada o refutada de manera satisfactoria.

Aproximadamente, a la mitad del documental emerge la figura del siguiente condenado por el juicio de los testimonios: Margarita López Portillo, la hermana del presidente en turno, supuesta responsable del incendio y, en consecuencia, 
de la pérdida cultural que implicó. Como afirma en entrevista el propio director del largometraje,

Si ese material existía y estaba dentro de esas bóvedas, y se quemó junto con todo nuestro acervo fílmico, pues fue un día de gran celebración para muchas personas que quizá estaban preocupadas por la posible fuga de un material fílmico que podía traer muchas evidencias a futuro (2012).

Gibrán Bazán resume en esa frase una de las hipótesis sostenidas en su documental —lo que hemos llamado líneas atrás 'tercera trama implícita'-. "El incendio fue por una estupidez de Margarita López Portillo, que todavía lamentamos porque se quemaron muchas películas que eran únicas en el mundo" (2012), afirma óscar Menéndez, acusación que se repite entre los testimonios, muchos de los cuales añaden información sobre la mala gestión de la directora de RTC de esa época (ejemplo del nepotismo del sexenio de 1976 a 1982), y las pésimas condiciones estructurales y de organización del recinto (incumplimiento en el pago de seguros, falta de mantenimiento en los aspersores). "Cuando la irresponsabilidad se une con la pendejez y la mala leche, pues ya ves, se queman las cinetecas" (2012), sentencia la exdirectora de programación de la Cineteca Nacional, Susana López Aranda. Esta afirmación se encadena con la opinión de Nicolás Echevarría, quien asegura que "[s]e quemaron joyas [...] todo el archivo de [Plutarco Elías] Calles, probablemente el archivo de [Álvaro] Obregón [...], era el acervo principal, depositario de toda la tradición cinematográfica" (2012).

Es significativo ver que, tras los lamentos de los entrevistados por la destrucción de la antigua cineteca, aparecen en pantalla, con musicalización melancólica de fondo, stills de obras maestras de la cinematografía mundial, como Historias de Tokio (1953), Persona (1966), La pasión de Juana de Arco (1928), Los 400 golpes
(1959), Ladrón de bicicletas (1950), Los siete samuráis (1954), La strada (1954) y La tierra de la gran promesa (1957), película de Andrzej Wajda que se estaba proyectando en la sala Fernando de Fuentes al momento de la explosión. Obviamente, ninguno de estos filmes se perdió, pero su proyección intercalada con las escenas del incendio, tomadas del noticiero televisivo del periodista Jacobo Zabludovsky emitido aquella noche, funciona para que el espectador dimensione la trascendencia de un evento que, hasta antes de ver el documental, muy probablemente desconocía. Es decir, sirve para concientizarlo sobre la permanente tensión entre la memoria y el silencio impuesto.

Con estos datos en mente, resulta interesante constatar que Los rollos perdidos se suma a una tendencia del género documental mexicano reciente, cuya prioridad se encuentra en el rescate de acontecimientos del siglo pasado (y de la primera década del XXI, a partir de la guerra contra el narcotráfico impulsada por el presidente Felipe Calderón), y en la difusión de datos que, en efecto, buscan repercutir en la formación crítica del público espectador. Particularmente, este cine alude a las violencias estructurales, pues, como expresa Siboney Obscura con respecto al documental fílmico de nuestro país,

[1]as situaciones de violencia del Estado contra amplios sectores de la población civil se perciben, a nivel social, como una herida que requiere de un largo proceso de cicatrización, en el que la memoria colectiva es fundamental, porque por medio de ella se generan las representaciones de dichos sucesos y su valoración, ya sea positiva o negativa (2013: 168).

De tal forma, sin llegar a ser un producto cultural masivo, el cine documental, o al menos una buena parte de él, ejerce en la actualidad como medio de reconstrucción, preservación e interpretación de la memoria. Es el caso del largometraje de Bazán, en específico en lo concerniente a 


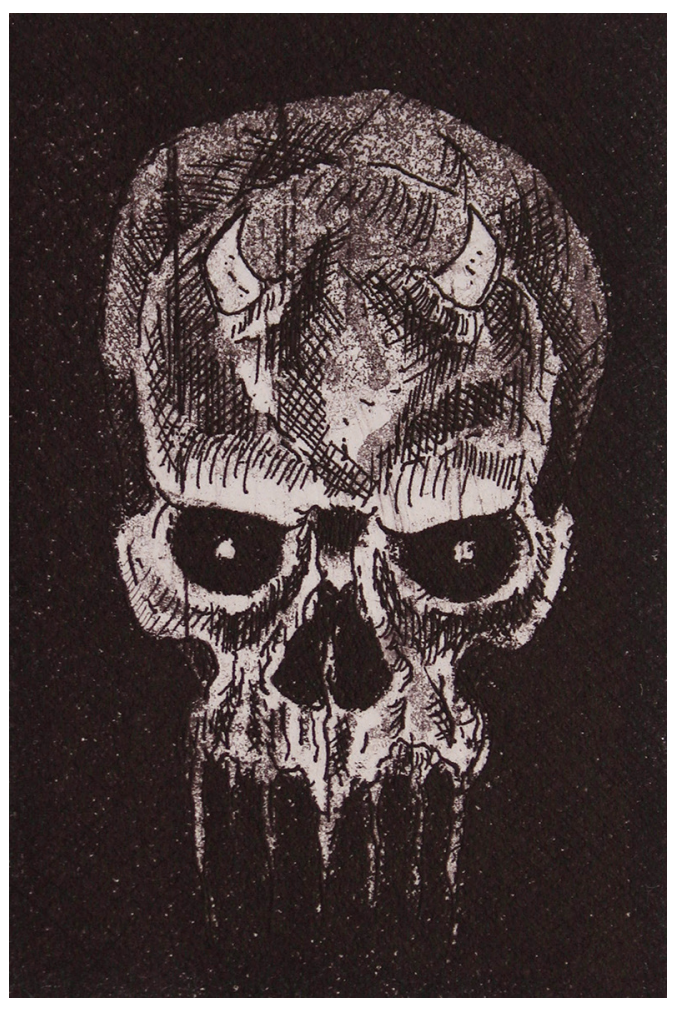

Delirios de una agonia prolongada (s/f ). Colografía: Juan Manuel Martínez Jaramillo. Prohibida su reproducción en obras derivadas.

la matanza del 2 de octubre de 1968 y el incendio de la Cineteca Nacional (paradójicamente, un espacio destinado a conservar la memoria audiovisual). Tal como anuncia el eslogan en la portada del DVD de la película, autocatalogada como la primera que 'rompe el silencio' mediante una retórica y una estructura de investigación, el largometraje logra trazar una conexión inesperada entre ambos sucesos.

"Sólo seis meses después del siniestro comenzaron los trabajos de demolición de las ruinas de la Cineteca Nacional [dice la voz en off], sin haber permitido en ese lapso el acceso a especialistas externos para analizar los escombros" (2012), se afirma en el documental. La pregunta, o mejor dicho, la sospecha de un posible sabotaje, es sembrada en el espectador cuando el equipo de filmación presenta un mapa del piso donde ocurrió la explosión y conjetura sobre el contenido almacenado en la bóveda que, presuntamente, estalló primero. La tercera trama, que no es parte de la investigación testimonial pero sí de la persuasión del trabajo documental, queda establecida en este momento de la película. Según Jesús Adolfo Soto Curiel,

[p]ara recrear en pantalla la realidad que se nos presenta, en el documental que se apoya en el testimonio oral cobra una gran importancia la construcción visual, la cual se realiza con base en la imagen, que retrata el entorno en que viven y habitan quienes nos ofrecen su oralidad (2017: 82).

Dicha hipótesis nos permite volver a la analogía referida entre el género documental y la ficción detectivesca.

Muy cerca del desenlace de la obra de Bazán, encontramos una secuencia ilustrativa en la que cuatro jóvenes (el equipo de Los rollos perdidos) figuran en una mise-en-scène del ejercicio investigativo situada en una especie de búnker 
semiiluminado (una atmósfera entre conspiratoria y exploradora). Están de pie alrededor de una mesa sobre la que miran el croquis de la cineteca incendiada y van señalando los puntos donde, suponen, se generó la explosión. Es en esta escena breve donde podemos distinguir una suerte de alegoría audiovisual del trabajo del director, quien examina, crea conjeturas, recaba testimonios y los organiza para que, en conjunto y gracias al trabajo de montaje adecuado, se convierta en una historia que, si tiene éxito, apelará de distintas formas al público espectador y quizá fomente en él una apropiación de dicho relato, integrándolo a su experiencia personal, pues "[e]n cada documental hay por lo menos tres historias que se entrelazan: la del documentalista, la de la película y la del público" (Nichols, 2013: 117).

Memoria y silencio, culpabilidad y complicidad, son los binomios más recurrentes en los últimos minutos del largometraje, a manera de conclusión sobre el objetivo enunciado en el póster y en la portada del DVD. Romper el silencio, ambición del trabajo dirigido por Bazán, se vuelve el leitmotiv de ambas tramas, y aunque la tercera (la de las suposiciones sobre lo que estaba en la cineteca) no queda resuelta, ofrece elementos para que el espectador se cuestione sobre las razones del silencio y la impunidad, las interprete y construya sus hipótesis o conclusiones. Más allá de señalar responsables o culpables, LoS rollos perdidos intenta, como buena parte de las obras de este género cinematográfico, activar la conciencia ética de quien lo ve y, a partir de ello, detonar la reflexión social sobre la persistencia de la memoria y el cumplimiento de la justicia, en particular de aquellos hechos que transformaron directamente la historia cultural y social del país.

\section{REFERENCIAS}

Bazán, Gibrán (dir.) (2012), Los rollos perdidos, México, Marsash Producciones/Xibalbá Films.

CONACULTA (2012), Proyecto Cineteca Nacional Siglo XXI, México, CONACULTA.

Nichols, Bill (2013), Introducción al documental, México, UNAM.

Obscura Gutiérrez, Siboney (2013), "Rescate de la memoria: la guerra sucia en el nuevo documental mexicano", La Colmena, núm. 80, pp. 167-172.

Pelayo Rangel, Alejandro (1993), Servando González, en Memoria del cine mexicano, IMCINE/CONACULTA.

Soto Curiel, Jesús Adolfo (2017), Recordar en presente. Cine documental y memoria en México, Mexicali, Universidad Autónoma de Baja California. 